\title{
In-Vivo High Dynamic Range Vector Flow Imaging
}

\author{
Villagómez Hoyos, Carlos Armando; Stuart, Matthias Bo; Jensen, Jørgen Arendt
}

\section{Published in:}

Proceedings of IEEE International Ultrasonics Symposium

Link to article, DOI:

10.1109/ULTSYM.2015.0424

Publication date:

2015

Document Version

Peer reviewed version

Link back to DTU Orbit

Citation $(A P A)$ :

Villagómez Hoyos, C. A., Stuart, M. B., \& Jensen, J. A. (2015). In-Vivo High Dynamic Range Vector Flow Imaging. In Proceedings of IEEE International Ultrasonics Symposium IEEE.

https://doi.org/10.1109/ULTSYM.2015.0424

\section{General rights}

Copyright and moral rights for the publications made accessible in the public portal are retained by the authors and/or other copyright owners and it is a condition of accessing publications that users recognise and abide by the legal requirements associated with these rights.

- Users may download and print one copy of any publication from the public portal for the purpose of private study or research.

- You may not further distribute the material or use it for any profit-making activity or commercial gain

- You may freely distribute the URL identifying the publication in the public portal

If you believe that this document breaches copyright please contact us providing details, and we will remove access to the work immediately and investigate your claim 
Paper presented at the IEEE International Ultrasonics Symposium, Taipei, Taiwan, 2015:

\section{In-Vivo High Dynamic Range Vector Flow Imaging}

Carlos A. Villagómez Hoyos, Matthias Bo Stuart and Jørgen Arendt Jensen

${ }^{1}$ Center for Fast Ultrasound Imaging,

Biomedical Engineering group, Department of Electrical Engineering, Bldg. 349,

Technical University of Denmark, DK-2800 Kgs. Lyngby, Denmark

To be published in Proceedings of IEEE International Ultrasonics Symposium, Taipei, Taiwan, 2015. 


\title{
In-Vivo High Dynamic Range Vector Flow Imaging
}

\author{
Carlos A. Villagómez-Hoyos, Matthias Bo Stuart and Jørgen Arendt Jensen \\ Center for Fast Ultrasound Imaging, Department of Electrical Engineering, \\ Technical University of Denmark, DK-2800 Lyngby, Denmark
}

\begin{abstract}
Current vector flow systems are limited in their detectable range of blood flow velocities. Previous work on phantoms has shown that the velocity range can be extended using synthetic aperture directional beamforming combined with an adaptive multi-lag approach. This paper presents a first invivo example with a high dynamic velocity range. Velocities with an order of magnitude apart are detected on the femoral artery of a 41 years old healthy individual. Three distinct heart cycles are captured during a 3 secs acquisition. The estimated vector velocities are compared against each other within the heart cycle. The relative standard deviation of the measured velocity magnitude between the three peak systoles was found to be $5.11 \%$ with a standard deviation on the detected angle of $1.06{ }^{\circ}$. In the diastole, it was $1.46 \%$ and $6.18^{\circ}$, respectively. Results proves that the method is able to estimate flow in-vivo and provide quantitative results in a high dynamic velocity range. Providing velocity measurements during the whole cardiac cycle for both arteries and veins.
\end{abstract}

\section{INTRODUCTION}

Vector flow systems using ultrasound have become more appealing as they can accurately capture complex flow features presented in the vasculature compared to their 1-D counterpart. These newly available features have the potential of providing more insight into the progression of vascular diseases, and prove more useful for an accurate quantification of blood flow derived parameters (e.g. vorticity, pressure gradients).

Vector flow systems have been traditionally based on phase shift estimators [1]. These systems are limited in their detectable range of blood flow velocities due to the limited amount of data for velocity estimation. A choice between visualizing diastolic or systolic flow needs to be made by the physician. An adjustment of the pulse repetition frequency $f_{p r f}$ is frequently performed to avoid aliasing. Aliasing occurs when the frequency being sampled is greater than half the sampling rate, and this is a well known artefact in 1-D flow systems. However, in vector flow systems aliasing errors are more complex to detect than for 1-D estimators. For 2-D imaging, aliasing could be present in either or both of the velocity components. For example, in the particular case of cross-beam techniques, if only one receive signal is aliased a large and dominant lateral component is detected, as investigated in [2]. To mitigate these effects, several authors have proposed the use of higher number of emissions in combination with leastsquares methods [3] and aliasing resistant algorithms [4].

Time shift estimators were introduced for ultrasound flow estimation in the mid 80s by Bonnefous[5], and it was shown to overcome the aliasing limit. Time shift estimators use the displacement between successive echo signals of the scatterers.
The technique showed promising results, as it presented a better performance than phase shift techniques [6]. Additionally, time shift estimators perform better with short pulses, thus, no spatial resolution is sacrificed. However, the performance of the method severely deteriorates for larger beam-to-flow [7]. This was due to the rapid decorrelation of the blood signal, since the blood scatterers stayed inside the ultrasound beam for a shorter amount of time. To compensate for this the use of broader beams and parallel beamformers was suggested by Bonnefous [8], which generated a signal transverse to the ultrasound field. However, the approach solely worked for flow that was transverse to the ultrasound beam. Later, Jensen and Lacasa suggested using signals focused along the flow direction to solve the problem [9]. The approach, called directional beamforming, proved to be highly accurate in estimating flow velocities, and therefore was further investigated in [10], [11]. Jensen and Nikolov, furtherly improved the method by combining it with synthetic aperture techniques[12], which made the method more robust at detecting the correct angle with the proposed angle estimator [13]. Finally, the velocity range of the method was extended by Villagomez [14] using a multi-lag approach using the fact that synthetic aperture techniques provides continuous data. The method was validated on simulations and phantoms.

In this paper an in-vivo example of the proposed method is shown. The method is first described in Section II. The imaging sequence is described in Section II-C. A brief description of the algorithm is given in Section II-A. Finally, the results of an in-vivo acquisition on the femoral artery and vein of a 41 years old individual are presented in Section II-D.

\section{Methods}

The directional velocity estimation is performed using the synthetic aperture approach developed by Jensen and Nikolov [15], and briefly described in Section II-A. Here diverging ultrasound waves are emitted using virtual sources, as described in Section II-C. The received multi-channel data are focused at any set of points within the interrogated region. The consecutive beamformed lines are correlated at mutiple lags and an adaptive algorithm selects the correct lag, as proposed in [14] and briefly described in Section II-B.

\section{A. Vector Flow Imaging}

The blood flow is tracked by focusing along directional lines $g\left(r^{\prime}, \theta_{m}\right)$ in the polar grid $\left(r^{\prime}, \theta_{m}\right)$, centred at the estimation point $\vec{x}$, as shown in Fig 1 . Vessel wall echo-canceling is performed before the velocity estimation in a similar fashion 


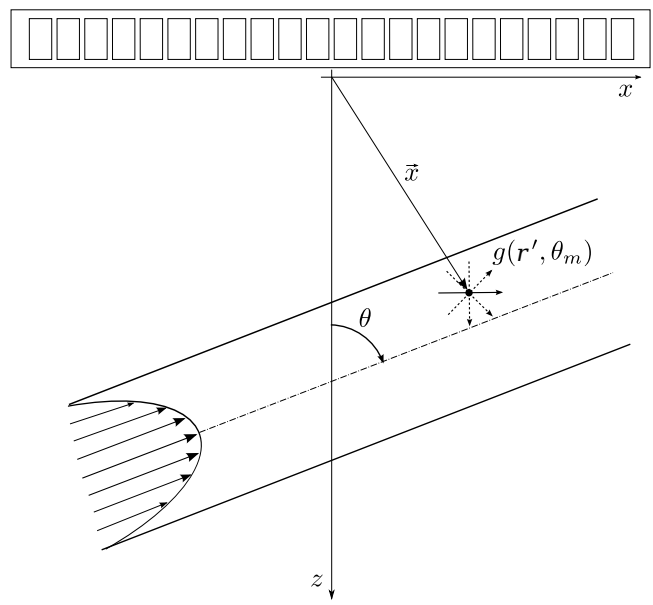

Fig. 1. Directional beamforming setup for a polar grid $g\left(r^{\prime}, \theta_{m}\right)$ centred at a single estimation point $\vec{x}$.

as described in [16]. The directional velocity estimation is performed as described by Jensen [10], by beamforming focused lines.

The focused lines $g\left(r^{\prime}, \theta_{m}\right)$ are correlated for lines acquired $T_{\text {eff }}$ seconds apart. The correlation is calculated along a discrete set of angles $\theta_{m}$, as follows,

$$
R_{12}\left(l, \theta_{m}\right)=\sum_{k=-N_{\text {xcorr }} / 2}^{N_{\text {xcorr }} / 2} g^{t}\left(k, \theta_{m}\right) g^{t+T_{\text {eff }}\left(k+l, \theta_{m}\right),}
$$

where $l$ is the correlation lag and $N_{x c o r r}$ is the discrete length of the directional signals.

A number of cross-correlations, $N_{x c}$ are averaged under the assumption that the scatterer's motion can be considered quasi-static during successive acquisitions. The velocities are estimated by finding the maximum of the correlation function (1). For increased accuracy, a second-order polynomial is fitted to the cross-correlation around $l_{\max }\left(\theta_{m}\right)$, and the position of the maximum correlation, $\hat{l}_{\max }$, is found by the interpolation formula given in [7].

The directional velocity estimate along the direction $\theta_{m}$ is given by

$$
V\left(\theta_{m}\right)=\frac{\hat{l}_{\max }\left(\theta_{m}\right) \cdot d_{r}}{T_{e f f}}
$$

where $d_{r}$ is the spatial sampling interval.

\section{B. Adaptive multi-lag}

The correlation time $T_{e f f}$ is selected adaptively from a set of discrete times multiple of the pulse repetition frequency $T_{e f f}=\mathrm{Lag} \cdot T_{P R F}$, where $\mathrm{Lag}$ is a positive integer value.

An optimal Lag is selected to attain more accurate estimates. The criteria for selecting the optimal Lag is to lower the relative standard deviations. As the nature of the blood flow is pulsatile, the relative standard deviation cannot be estimated over the whole measurement period. Therefore, it is necessary to generate a piecewise linear approximation of the flow waveform by fitting a line to the velocity estimates into a small time window. The size of the time window segments is selected, so that the approximation resembles the flow waveform as close as possible. The value used in this work is $6 \mathrm{~ms}$ or 15 velocity estimates.

The optimal Lag is selected by minimizing the standard deviation of subtracting a piecewise linear approximation from the velocity estimate at each point as denoted by

$$
\operatorname{Lag}\left(\mathbf{r}_{\mathbf{x}}, t n\right)=\arg \min _{\text {Lag }}\left[\operatorname{std}\left\{\hat{v}^{\prime}\left(\mathbf{r}_{\mathbf{x}}, t_{n}, \operatorname{Lag}\right)-\hat{v}_{p l}\left(\mathbf{r}_{\mathbf{x}}, t_{n}, \operatorname{Lag}\right)\right\}\right],
$$

where $\hat{v}^{\prime}\left(\mathbf{r}_{\mathbf{x}}, t_{n}\right.$, Lag $)$ is the segment from the estimated velocity and $\hat{v}_{p l}\left(\mathbf{r}_{\mathbf{x}}, t_{n}, L a g\right)$ is the piecewise linear approximation at that segment.

Finally, the $\operatorname{Lag}\left(\mathbf{r}_{\mathbf{x}}, t n\right)$ is smoothed using a median filter (3 [mm] x $20[\mathrm{~ms}])$ to reduce Lag jumps.

\section{Measurement setup}

A 128-element linear array probe connected to the experimental ultrasound scanner, SARUS [17], is used in the scanning. A duplex synthetic aperture (SA) sequence with virtual sources is emitted to acquire both B-mode and flow data sets. The emissions are interleaved, so that a B-mode emission is transmitted for every five flow emissions. An effective pulse repetition frequency is consequently $P R F_{\text {eff }}=P R F /(5+1)$.

The SA B-mode image consist of 128 individual emissions with virtual sources located behind the transducer using a 16 element sub-aperture. A 3-cycle sinusoidal pulse weighted by a $50 \%$ Tukey window is used as excitation waveform.

The flow sequence is implemented using a 64-element sub-aperture to increase the amount of emitted energy. The virtual sources are located behind the transducer as well. The transmitted wavefront is directed towards a region of interest (ROI), so the ROI is completely insonified in every emission (Fig. 2). A linear frequency modulated (FM) chirp tapered with a Tukey window is used as excitation wave. The excitation has a duration of 1.5 microseconds including the tapered region, with a frequency span from $3.5 \mathrm{MHz}$ to $9.5 \mathrm{MHz}$. A $40 \%$ tapering is applied to reduce the effects of sidelobes. [18]. The transducer and acquisition parameters are listed in Table I.

The acoustic output of the sequence is measured for the two imaging modes using the scheme described in [19]. The measured intensities must satisfy limits regulated by the U.S. Food and Drug Administration (FDA). These limits concern the mechanical index, $M I \leq 1.9$, the derated spatial-peaktemporal-average intensity, $I_{\text {spta }} \leq 720 \mathrm{~mW} / \mathrm{cm}^{2}$ [20]. The measured values are $M I=0.83$ and a $I_{\text {spta }}=534 \mathrm{~mW} / \mathrm{cm}^{2}$, which are both below the FDA limits. The transducer surface temperature was also tested, where the transducer surface should not exceed an increase of $30^{\circ} \mathrm{C}$ and $6^{\circ} \mathrm{C}$ Celsius in air and in a simulated usage test, respectively. The maximum pulse repetition frequency (PRF) was adjusted to comply with these regulations, and was found to be $15 \mathrm{kHz}$ for the current emission setup. 
Table I

TRANSDUCER AND ACQUISITION PARAMETERS

\begin{tabular}{|c|c|c|c|c|}
\hline \multicolumn{2}{|l|}{ Transducer } & \multicolumn{3}{|c|}{ Transmit Parameters } \\
\hline Parameter & Value & Parameter & B-mode & Flow \\
\hline Trandsucer type & Linear array & F-number & -1 & -3.5 \\
\hline Number of transducer elements & 128 & Number of emitting elements & 16 & 64 \\
\hline Transducer element pitch & $0.3 \mathrm{~mm}$ & Apodization window & Hanning & \\
\hline Transducer element kerf & $0.035 \mathrm{~mm}$ & Number of emissions & 128 & 5 \\
\hline Transducer element height & $4 \mathrm{~mm}$ & Pulse repetition frequency (PRF) & $15 \mathrm{kHz}$ & \\
\hline Elevation focus & $20 \mathrm{~mm}$ & & & \\
\hline Center frequency & $8 \mathrm{MHz}$ & & & \\
\hline
\end{tabular}
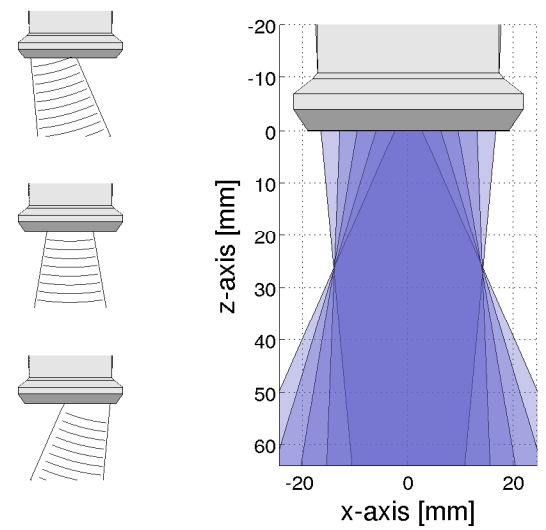

Fig. 2. Example of spherical waves used in the flow sequence (left). Overlay of the insonified area from each emission, and the actual region of interest shown in a darker shade (right).

\section{In vivo acquisition}

In-vivo acquisition are performed upon approval by The Danish National Committee on Biomedical Research Ethics. A healthy volunteer with no history of vascular or cardiac disease (41 years old male) entered the study after informed consent. The scan sequence was acquired during 3 seconds on a longitudinal view of the femoral artery and vein. The scan was recorded with the volunteer in standing position while performing dorsal and plantar flexion to simulate walking. The scan was carried out by an experienced radiologist.

\section{Measurement Results}

A $3 \mathrm{sec}$ acquisition is recorded on a femoral artery and vein simultaneously. The effective pulse repetition is $2500 \mathrm{~Hz}$ yielding 7500 velocity estimates in total. Fig. 3 (a) shows a single frame from the estimated vector flow image (VFI) at the time of a systole peak. The femoral artery presented no disturbed flow during the heart cycles, but marked reversed flow was seen during the beginning of diastole at the edges of the vessel. The magnitude of the reverse flow did not surpassed $0.05 \mathrm{~m} / \mathrm{s}$. A valve is also observed to disrupt the flow in the vein. However, this valve is not always visible in the B-mode image.

The velocity estimates were aligned at the three distinct peaks on the systole at the denoted line. Fig. 3 (b) and (c) shows the spatial and temporal repeatability of the measure- ment. The relative standard deviation (rel. std. dev.) respect the detectable velocity of $1 \mathrm{~m} / \mathrm{s}$ is the performance metric for the velocity magnitude. A standard deviation (std. dev.) is also calculated for the estimated angles. The spatial rel. std. dev. at the systole was $5.11 \%$ with an angle std. dev. of $1.06^{\circ}$. In the diastole, it was $1.46 \%$ and $6.18^{\circ}$, respectively. The temporal rel. std. dev. during the whole cardiac cycle was $5.06 \%$ with an angle std.dev. of $8.06^{\circ}$.

\section{CONCLUSION}

It has been shown that with the SA directional beamforming method flow during the whole cardiac cycle is available. Complex flow patterns are observed and the achieved high frame rate achieved make it possible to distinguish transient events that in other cases would be impossible to detect. The method have shown here to be robust and reliable as low standard deviations are obtained for distinct heart cycles at a high range of velocities.

\section{ACKNOWLEDGEMENT}

This work was supported by grant 82-2012-4 from the Danish Advanced Technology Foundation and by BK Medical Aps.

\section{REFERENCES}

[1] B. Dunmire, K. W. Beach, K.-H. Labs., M. Plett, and D. E. Strandness, "Cross-beam vector Doppler ultrasound for angle independent velocity measurements," Ultrasound Med. Biol., vol. 26, pp. 1213-1235, 2000.

[2] A. Swillens, L. Løvstakken, J. Kips, H. Torp, and P. Segers, "Ultrasound simulation of complex flow velocity fields based on computational fluid dynamics," IEEE Trans. Ultrason., Ferroelec., Freq. Contr., vol. 56, no. 3, pp. 546-556, 2009.

[3] B. Y. Yiu, S. S. Lai, and A. C. Yu, "Vector projectile imaging: timeresolved dynamic visualization of complex flow patterns." Ultrasound Med. Biol., vol. 40, no. 9, pp. 2295-2309, sept 2014

[4] J. Flynn, R. Daigle, L. Pflugrath, P. Kaczkowski, and K. Linkhart, "Estimation and display for vector doppler imaging using planewave transmissions," Proc. IEEE Ultrason. Symp., pp. 413-418, 2011.

[5] O. Bonnefous and P. Pesqué, "Time domain formulation of pulseDoppler ultrasound and blood velocity estimation by cross correlation," Ultrason. Imaging, vol. 8, pp. 73-85, 1986.

[6] A. P. G. Hoeks, T. G. J. Arts, P. J. Brands, and R. S. Reneman, "Comparison of the performance of the rf cross correlation and Doppler autocorrelation technique to estimate the mean velocity of simulated ultrasound signals," Ultrasound Med. Biol., vol. 19, pp. 727-740, 1993.

[7] S. G. Foster, P. M. Embree, and W. D. O'Brien, "Flow velocity profile via time-domain correlation: Error analysis and computer simulation," IEEE Trans. Ultrason., Ferroelec., Freq. Contr., vol. 37, pp. 164-175, 1990.

[8] O. Bonnefous, "Measurement of the complete (3D) velocity vector of blood flows," in Proc. IEEE Ultrason. Symp., 1988, pp. 795-799. 


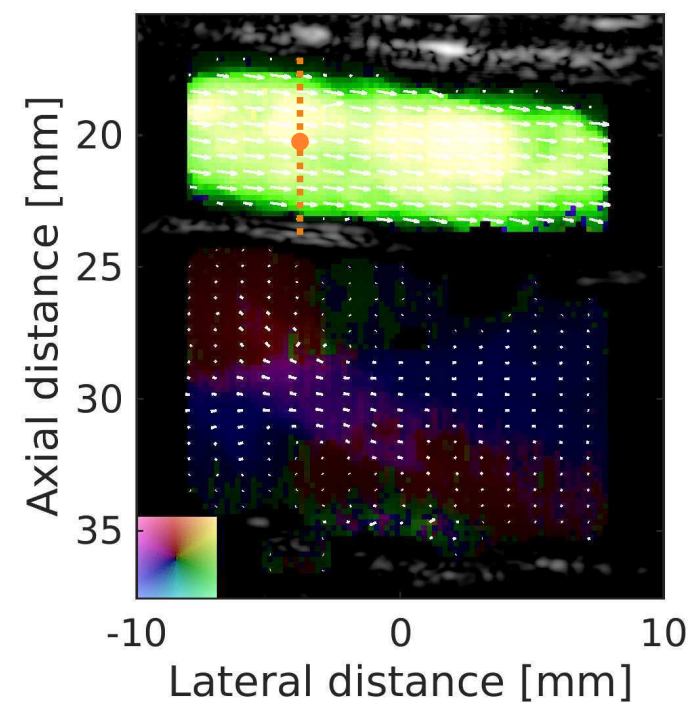

a)

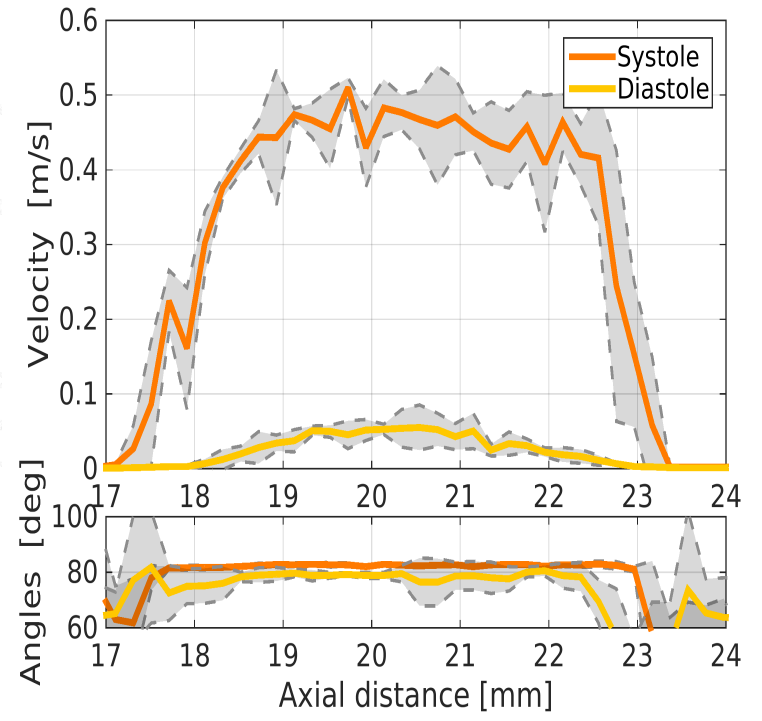

b)
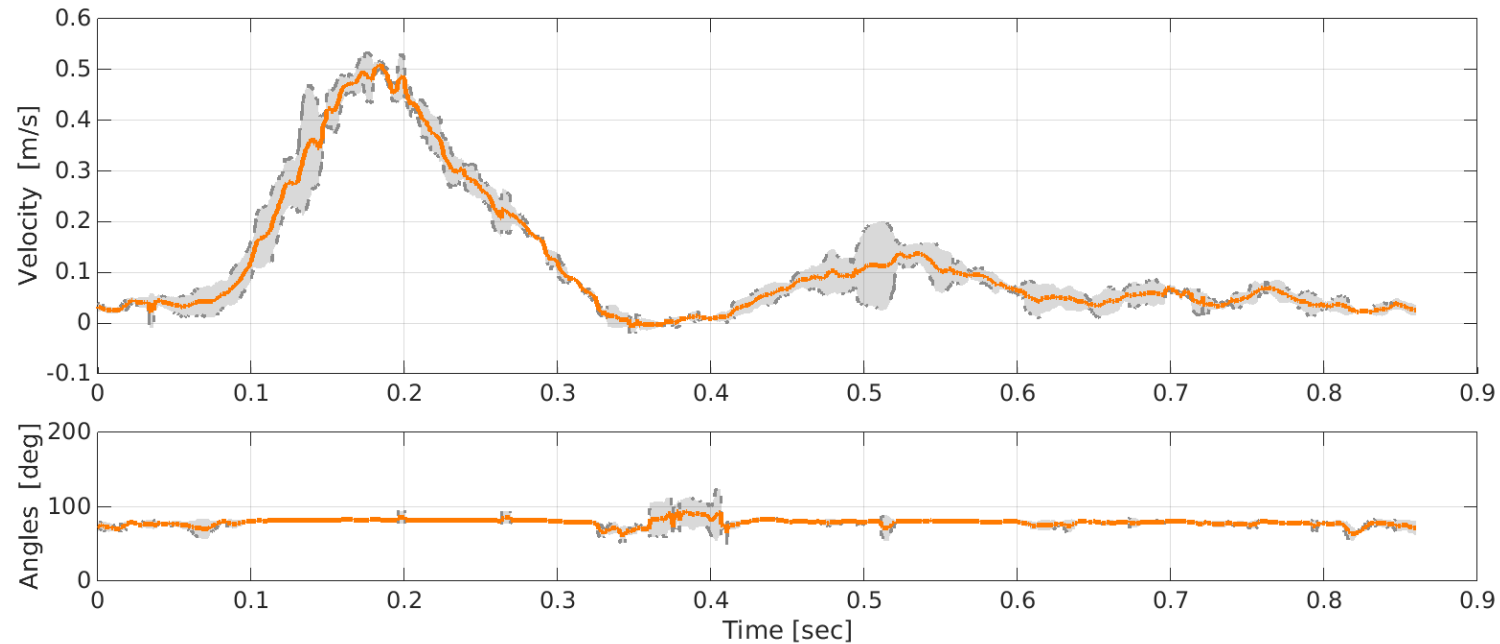

c)

Fig. 3. In-vivo vector flow estimates of the femoral artery and vein of a healthy 41 years old male. Vector flow image of the flow during the systole is shown in (a). The three distinct systole peaks were aligned on the denoted line. The spatial repeatability of the measurement is plotted in (b) for both the systole and diastole. The temporal repeatability during the whole cardiac cycle in the denoted point is plotted in (c).

[9] J. A. Jensen and I. R. Lacasa, "Estimation of blood velocity vectors using transverse ultrasound beam focusing and cross-correlation," in Proc. IEEE Ultrason. Symp., 1999, pp. 1493-1497.

[10] J. A. Jensen, "Directional velocity estimation using focusing along the flow direction: I: Theory and simulation," IEEE Trans. Ultrason. Ferroelec., Freq. Contr., vol. 50, pp. 857-872, 2003.

[11] J. A. Jensen and R. Bjerngaard, "Directional velocity estimation using focusing along the flow direction: II: Experimental investigation," IEEE Trans. Ultrason., Ferroelec., Freq. Contr., vol. 50, pp. 873-880, 2003.

[12] J. A. Jensen and S. I. Nikolov, "Directional synthetic aperture flow imaging," IEEE Trans. Ultrason., Ferroelec., Freq. Contr., vol. 51, pp. 1107-1118, 2004.

[13] J. A. Jensen and N. Oddershede, "Estimation of velocity vectors in synthetic aperture ultrasound imaging." IEEE Trans. Ultrason., Ferroelec. Freq. Contr., vol. 25, pp. 1637-1644, 2006.

[14] C. A. Villagomez-Hoyos, M. B. Stuart, and J. A. Jensen, "Adaptive multi-lag for synthetic aperture vector flow imaging," in Proc. IEEE Ultrason. Symp., 2014, pp. 1722-1725.

[15] J. A. Jensen and S. I. Nikolov, "Transverse flow imaging using synthetic aperture directional beamforming," in Proc. IEEE Ultrason. Symp., 2002, pp. 1488-1492.

[16] A. D. Siggia and R. E. Passarelli, "Gaussian model adaptive processing (GMAP) for improved ground clutter cancellation and moment calculation," ERAD, pp. 67-73, 2004.

[17] J. A. Jensen, O. Holm, L. J. Jensen, H. Bendsen, S. I. Nikolov, B. G Tomov, P. Munk, M. Hansen, K. Salomonsen, J. Hansen, K. Gormsen, H. M. Pedersen, and K. L. Gammelmark, "Ultrasound research scanner for real-time synthetic aperture image acquisition," IEEE Trans. Ultrason., Ferroelec., Freq. Contr., vol. 52 (5), pp. 881-891, May 2005.

[18] T. Misaridis and J. A. Jensen, "Use of modulated excitation signals in ultrasound, Part II: Design and performance for medical imaging applications," IEEE Trans. Ultrason., Ferroelec., Freq. Contr., vol. 52, pp. 208-219, 2005.

[19] J. A. Jensen, M. F. Rasmussen, M. B. Stuart, and B. G. Tomov, "Rapid measurements of intensities for safety assessment of advanced imaging sequences," in Proc. SPIE Med. Imag., vol. 9040 90400Z-1, 2014.

[20] FDA, "510(k) guide for measuring and reporting acoustic output of diagnostic medical devices," Center for Devices and Radiological Health, FDA, Tech. Rep., 1985. 